\title{
Addressing barriers to quality of underutilized commodities and services for prevention and management of pre-eclampsia and eclampsia in Kenya
}

Charity Ndwiga

Population Council

Pooja Sripad

Population Council

Charlotte E. Warren

Population Council

Follow this and additional works at: https://knowledgecommons.popcouncil.org/departments_sbsr-rh

Part of the Demography, Population, and Ecology Commons, Family, Life Course, and Society Commons, International Public Health Commons, Maternal and Child Health Commons, and the Medicine and Health Commons

How does access to this work benefit you? Let us know!

\section{Recommended Citation}

Ndwiga, Charity, Pooja Sripad, and Charlotte E. Warren. 2018. "Addressing barriers to quality of underutilized commodities and services for prevention and management of pre-eclampsia and eclampsia in Kenya," Ending Eclampsia Final Study Report. Washington, DC: Population Council. 


\section{ENDING Eclampsia}

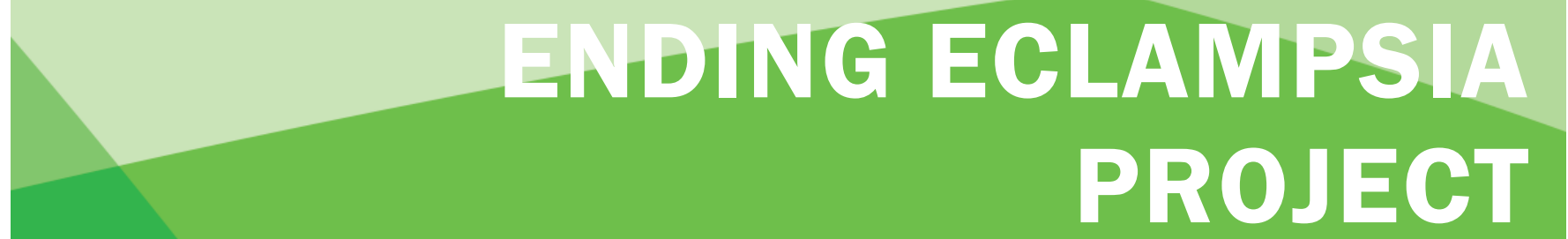

ADDRESSING BARRIERS TO QUALITY OF UNDERUTILIZED COMMODITIES AND SERVICES FOR PREVENTION AND MANAGEMENT OF PREECLAMPSIA AND ECLAMPSIA IN KENYA STUDY REPORT

Charity Ndwiga

Pooja Sripad

Charlotte Warren

August 2018 
Ending Eclampsia seeks to expand access to proven, under-utilized interventions and commodities for the prevention, early detection, and treatment of pre-eclampsia and eclampsia and strengthen global partnerships.

\section{POPULATION C. COUNCIL \\ Ideas. Evidence. Impact.}

The Population Council confronts critical health and development issues-from stopping the spread of HIV to improving reproductive health and ensuring that young people lead full and productive lives. Through biomedical, social science, and public health research in 50 countries, we work with our partners to deliver solutions that lead to more effective policies, programs, and technologies that improve lives around the world. Established in 1952 and headquartered in New York, the Council is a non-governmental, non-profit organization governed by an international board of trustees.

Population Council

4301 Connecticut Avenue NW, Suite 280

Washington, DC, 20008

Tel: +1. 877.237.9400

www.popcouncil.org

The Ending Eclampsia project is made possible by the generous support of the American people through the United States Agency for International Development (USAID) under the terms of USAID APS-OAA-1400048. The contents of this report are the sole responsibility of the Ending Eclampsia project and Population Council and do not necessarily reflect the views of USAID or the United States Government.

(c) 2018 The Population Council, Inc. 


\section{Abbreviations}

\begin{tabular}{|c|c|}
\hline ANC & Antenatal Care \\
\hline BP & Blood Pressure \\
\hline CHEW & Community Health Extension Worker \\
\hline CHMT & County Health Management Team \\
\hline CHV & Community Health Volunteer \\
\hline CMW & Community Midwife \\
\hline $\mathrm{C} / \mathrm{S}$ & Cesarean Section \\
\hline CU & Community Unit \\
\hline EML & Essential Medicines List \\
\hline EmONC & Emergency Obstetric and Neonatal Care \\
\hline ERC & Ethics Research Committee \\
\hline FGD & Focus Group Discussion \\
\hline FP & Family Planning \\
\hline HIV & Human Immunodeficiency Virus \\
\hline IDI & In-depth Interview \\
\hline KEMSA & Kenya Medical Supplies Authority \\
\hline KNH & Kenyatta National Hospital \\
\hline $\mathrm{MgSO}_{4}$ & Magnesium Sulphate \\
\hline MEDS & Mission for Essential Drugs and Supplies \\
\hline $\mathrm{MNCH}$ & Maternal, Newborn and Child Health \\
\hline MNH & Maternal and Newborn Health \\
\hline $\mathrm{PE} / \mathrm{E}$ & Pre-eclampsia and Eclampsia \\
\hline PHC & Primary Healthcare Center \\
\hline PNC & Postnatal Care \\
\hline RMHSU & Reproductive and Maternal Health Services Unit \\
\hline SCHMT & Sub-County Health Management Team \\
\hline TBA & Traditional Birth Attendant \\
\hline USAID & United States Agency for International Development \\
\hline VCT & Voluntary Counseling and Testing \\
\hline WHO & World Health Organization \\
\hline
\end{tabular}




\section{Table of Contents}

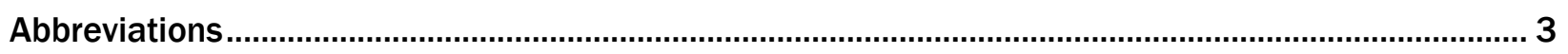

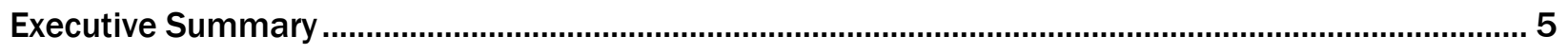

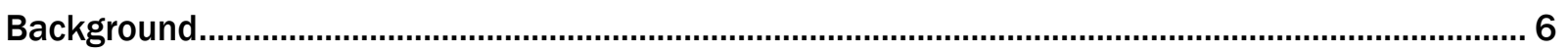

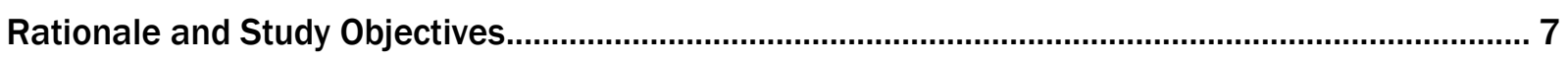

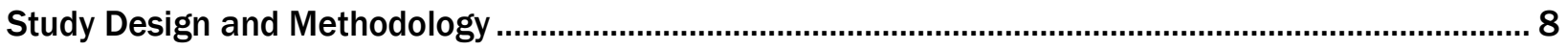

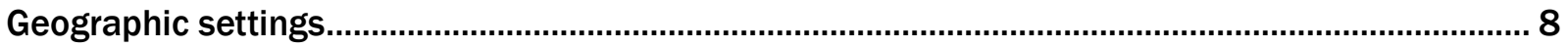

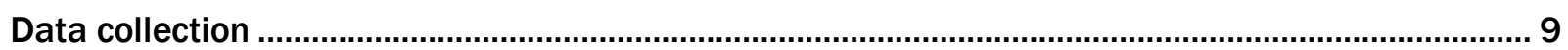

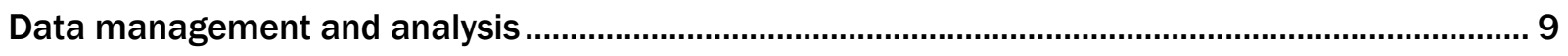

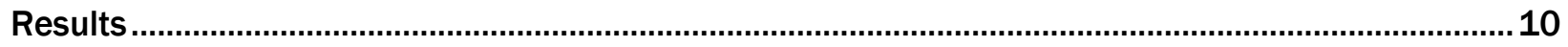

Policy and programming environment for pre-eclampsia and eclampsia .......................................10

Pre-eclampsia and eclampsia knowledge, perceptions and care-seeking behaviors ....................11

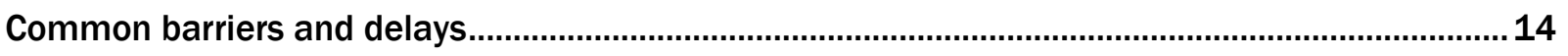

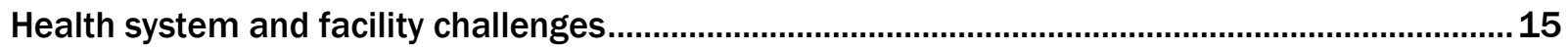

Availability of $\mathrm{MgSO}_{4}$, antihypertensive drugs, and essential equipment ...................................17

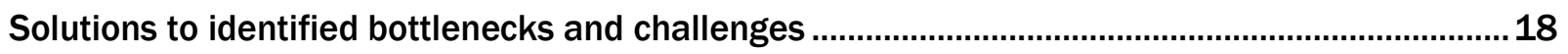

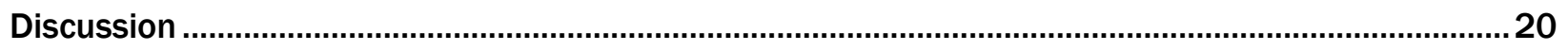

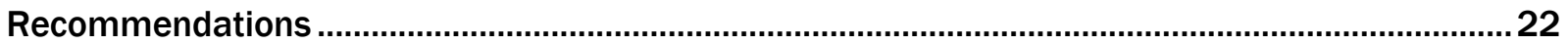

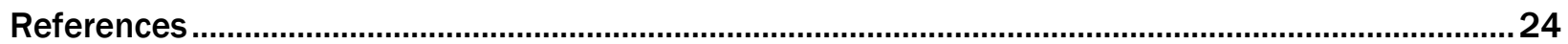




\section{Executive Summary}

The Ending Eclampsia project seeks to increase access to quality, under-utilized interventions and commodities for the prevention, detection, and management of pre-eclampsia and eclampsia (PE/E), including promoting correct use of antihypertensive drugs and magnesium sulphate $\left(\mathrm{MgSO}_{4}\right)$. This qualitative study explored health system bottlenecks that prevent access to quality maternal and newborn health (MNH) care in two Kenyan counties, Kitui and Kakamega, with a specific focus on PE/E.

This study explored policy implementation gaps in Kenya's newly-devolved county government structure, to: 1) assess the policy and health system environment for PE/E diagnosis, referral, and treatment, including potential supply chain bottlenecks, 2) investigate similarities and differences in PE/E knowledge, attitudes, and care-seeking behaviors among providers, women and community members, and 3) generate lessons for scaling up proven under-utilized PE/E interventions more effectively. We conducted a desk review of relevant Kenyan policies in addition to eight focus group discussions (FGDs) and 114 in-depth interviews (IDIs) with policy makers and program implementers, including those in commodity and supply logistics management, health workers at county and sub-county hospitals, primary healthcare (PHC) facilities, and community men and women, including those affected by PE/E.

Results suggest a good policy environment in Kenya: Policy and strategy documents clearly outline prevention, management, and referral for women with PE/E, but policy documents, training materials, and job aids are not available at facilities in rural health facilities or within communities. Some providers lack knowledge of the content of policy guidelines, training materials, and job aids even when they are available. Kenya's policy does allow use of $\mathrm{MgSO}_{4}$ at lower level facilities, but there is expressed need for increased focus on correct blood pressure (BP) measurement, urine testing, and improved community referrals.

$\mathrm{MgSO}_{4}$ is included in Kenya's essential medicines list (EML). Both counties, Kakamega and Kitui, rely on Kenya Medical Supplies Authority and Mission for Essential Drugs and Supplies to procure their drugs and commodities. Both agencies have clear guidelines to forecast, order, and procure the drugs, but some facilities fail to forecast their needs well, and sometimes counties do not have resources to pay on time, resulting in further delays. Lack of $\mathrm{MNH}$ commodity prioritization or poor coordination between national and county governments occasionally delays fund disbursement resulting in stock outs in $\mathrm{MgSO}_{4}$, antihypertensive drugs, urine tests, and $\mathrm{BP}$ machines.

When we spoke to women who experienced PE/E and community members, we found that they had inadequate knowledge of danger signs in pregnancy. Some normalized the symptoms resulting in delays in seeking care. Poverty, lack of male partners' support, myths/stereotypes and gender norms on health-seeking behavior were associated with delays in accessing care.

Key recommendations of this study include:

- Strengthen capacity for improved coordination and oversight between national and county governments to enhance smooth supply of essential MNH drugs and commodities,

- Build confidence through training and mentorship of providers at primary health care level on prevention and management of $\mathrm{PE} / \mathrm{E}$, particularly the use of $\mathrm{MgSO}_{4}$ /antihypertensive drugs.

- Develop, test and support innovative ways to inform communities on MNH danger signs and specifically $\mathrm{PE} / \mathrm{E}$ and the need for prompt care.

- Improve community and rural facility referral for patients with maternal complications, including PE/E, through improved communication and feedback loops with hospitals.

- Conduct implementation research study on sustaining provision of $\mathrm{MgSO}_{4}$ at lower level facilities. 


\section{Introduction}

This study is part of the Ending Eclampsia project, a five year cooperative agreement between United State Agency for International Development (USAID) and the Population Council, in partnership with the Kakamega and Kitui County ministries of Health in Kenya. Ending Eclampsia in Kenya builds on the project's prior work in four countries in addition to existing efforts in Kenya.

The project's overall goal is reducing maternal morbidity and mortality caused by pre-eclampsia and eclampsia (PE/E), by increasing use of appropriate, low cost interventions for preventing and treating severe PE/E in USAID priority countries. Landscape analyses in Nigeria, Bangladesh, and Pakistan helped understand knowledge and practices for different $\mathrm{PE} / \mathrm{E}$ aspects in those countries, including under-utilized interventions for $\mathrm{PE} / \mathrm{E}$ prevention and treatment, lower level health workers' abilities to screen and detect PE/E, and provide a modified loading dose of magnesium sulphate $\left(\mathrm{MgSO}_{4}\right)$ before referring women for follow up care.

Community beliefs, social dynamics, task shifting, and supply chain and health systems bottlenecks have emerged as relevant for preventing and managing PE/E. In 2002 Kenya adopted $\mathrm{MgSO}_{4}$ use for managing severe $\mathrm{PE} / \mathrm{E}$, and today health care provider training is being scaled up across the country as part of comprehensive maternal and newborn health (MNH) training program. This study sought to understand, through qualitative case study research, the policy, procurement, and supply challenges in sustaining an effective and supportive environment for MNH strategies for preventing and managing PE/E. To understand implementation bottlenecks and challenges-national, county, facility, and community-Population Council, in consultation with Kenya's ministries of Health and USAID's Kenya Mission, selected two counties (Kitui and Kakamega) for investigation; the Council has experience in these regions and counties and utilized national, county, sub-county, and community contacts to conduct this research.

\section{Background}

Hypertensive disorders in pregnancy, including pre-eclampsia and eclampsia (PE/E), affect morbidity and mortality for mothers and newborns worldwide. They account for 14 percent of the world's maternal deaths. The highest burden of $\mathrm{PE} / \mathrm{E}$ falls on lower middle-income countries ${ }^{1}$. Severe hypertension in pre-eclampsia, defined as a diastolic blood pressure (BP) $\geq 110$ and $\geq 160 \mathrm{~mm} \mathrm{Hg}$ systolic, requires immediate treatment of women with $\mathrm{MgSO}_{4}$ and an antihypertensive to effectively manage the complication and prevent progression to eclampsia ${ }^{2}$. In many settings, demand and supply side barriers to accessing maternal health services play significant roles in affecting PE/E burden.

Demand side barriers to quality ANC, emergency obstetric and newborn care (EmONC) and postnatal care (PNC) influence a woman and her family's birth preparedness and ability to access care and includes information they receive from health care providers about recognizing danger signs in pregnancy and symptoms of $P E / E^{3}$. Supply side barriers, including providers' inability to manage and refer to a hospital for safe delivery, limit a health system's capacity to detect and provide effective and efficient management of maternal health complications to prevent adverse maternal and newborn outcomes ${ }^{4}$. The gap between policy guidelines, and implementation of high impact interventions for maternal and neonatal care such as provision of $\mathrm{MgSO}_{4}$, an essential drug for $\mathrm{PE} / \mathrm{E}$ management poses one challenge in many countries; for instance, despite the presence of international or national guidelines around ANC, EmONC, and PNC, health systems are under-resourced to effectively act on these guidelines ${ }^{5}$. A study by the World Health Organization (WHO) showed that irrespective of clinical concurrence on the efficacy of $\mathrm{MgSO}_{4}$ in management of $\mathrm{PE} / \mathrm{E}$, its dosing regimen and administration mechanism varied globally. African facilities demonstrated low levels of $\mathrm{MgSO}_{4}$ availability (78\%), formal protocol ability (83\%), and protocol distribution to staff $(25 \%)^{6}$. 


\section{$\mathrm{PE} / \mathrm{E}$ burden, policy, and programming in Kenya}

In Kenya, between 2003 and 2014, the proportions of mothers accessing ANC and EmONC increased by eight and 20 percentage points, respectively, and dropped by 38 percent, from 590 to 362 maternal deaths per 100,000 live births ${ }^{7}$. Hypertensive disorders in pregnancy including PE/E-related conditions and hemorrhage remain among the most common causes of maternal deaths in Kenya and demonstrate increasing incidence in Kenya ${ }^{1,8}$. One single county study found that 23 percent of maternal deaths were due to pre-eclampsiaspecifically a failure to recognize danger signs $(44 \%)$ and ignorance of available services $(14 \%)^{5}$.

Kenya's Ministry of Health $(\mathrm{MoH})$ guidelines for management of severe PE/E adapts the WHO guidelines within the local context ${ }^{9}$. In April 2016, Kenya launched a high impact action plan, which includes prevention and management of $\mathrm{PE} / \mathrm{E}$, to protect mothers and newborns through scaling up effective interventions in $\mathrm{MNH}^{10}$. A complementary investment plan was developed to actualize the scale up of the use of $\mathrm{MgSO}_{4}$, improve provider capacity, and meet health systems requirements to implement the high impact evidence-based interventions ${ }^{11}$. There are still gaps, however, between policy direction and providers' knowledge, practices, and attitudes. A study in a hospital in North Eastern Kenya showed that the majority of healthcare professionals handling women with severe PE/E were nurses (61\%), followed by clinical officers (23\%) and trained doctors (15\%). Although a majority of health care workers alluded to the existence of guidelines in the Hospital, medical records of management of severe $\mathrm{PE} / \mathrm{E}$ patients fell short of the guideline recommendations ${ }^{12}$.

\section{Rationale and Study Objectives}

Despite the existence of health policies and guidelines at the national level and a range of provider trainings in $\mathrm{MNH}$, women still face challenges in accessing quality ANC and EmONC services to prevent and manage PE/E. There is little research on the gap between national and county level policy and procedures, including observation of supply chains, particularly in the context of devolution and free maternity services. This study aims to understand the links between the quality of ANC, under-utilization of EmONC, and quality of PNC, and the multilevel challenges facing health systems in preventing and managing PE/E. A case study approach lends itself to providing lessons for scale up of effective MNH programming in the new devolved governance structure.

Specific study objectives include to:

1. Assess the policy and health systems environment related to PE/E prevention, diagnosis, referral, and treatment, including identifying potential bottlenecks in the supply chain.

2. Investigate the similarities and differences in knowledge, attitudes, and care-seeking behaviors surrounding $\mathrm{PE} / \mathrm{E}$ across community, facility, and county perspectives.

3. Develop county case studies of PE/E care-provision and care-seeking to provide lessons for scaling up more effective policy and programming to other counties and at the national level.

This study investigates the views of public health officials on the national, county, sub-county and community levels. It engages with midwives, doctors, community midwives $(\mathrm{CMWs})^{1}$, community health extension workers (CHEWs), community health volunteers (CHVs), and traditional birth attendants (TBAs) in both counties to understand the knowledge and experience of service providers in being able to detect and treat PE/E, including assessing supply chain gaps in guideline implementation through devolution. Exploring the perceptions of communities and women who have experienced PE/E sheds light on local attitudes and care-seeking behaviors.

1 Community midwives are formally trained as nurse/midwives at Medical Training Centres and previously worked in the health system 


\section{Study Design and Methodology}

This study adopts a qualitative case study approach and triangulates across various data collection methods including in-depth interviews (IDIs), focus group discussions (FGDs), and a desk review. Case studies are wellsuited to understanding complex social phenomena, including organizational and managerial processes within health systems that may have implications for a range of inter-related maternal health attitudes, behaviors and outcomes ${ }^{13}$. In our study, we present cross-county examples to better understand the health systems gaps around PE/E knowledge and attitudes, prevention and management, and ANC accessibility and acceptability. The county sites are bounded, have low facility delivery, are geographically distant (Eastern and Western regions $)^{14}$, and have had historical and recent $\mathrm{MNH}$ capacity building support ${ }^{15},{ }^{16}, 17$.

\section{Geographic settings}

The study took place in two counties, Kitui (Eastern) and Kakamega (Western) as well as Nairobi County (where national policy makers sit). Kitui and Kakamega are divergent cases with respect to maternal health service provision and county dynamics, but sites that were relatively similar on other socio-demographics and basic health service utilization (Table 1). The two counties also benefit from USAID and partner support in supplying $\mathrm{MNH}$ and family planning (FP) commodities and equipment as well as in provider trainings in EmONC, quality of care, and, most recently, respectful maternity care.

Kitui and Kakamega have similar levels of education, female literacy, agricultural occupations, age at first marriage, age at first birth, FP use, and access to skilled maternal health services (Table 1). In both counties, around 60 percent of women who attended ANC were informed of signs of pregnancy complications. Proportions of women with BP taken, urine measured, and blood tested were higher in Kitui than in Kakamega. Women living Kitui and Kakamega counties are less likely to deliver with a skilled attendant than Kenyan women on average (61.2\%), and less likely to receive PNC in Kitui (50\%) and Kakamega (35\%)

\section{Table 1. Socio-demographic and basic health characteristics of target population}

\begin{tabular}{|c|c|c|c|}
\hline & Kitui & Kakamega & Kenya \\
\hline Population & 1.1 million & 1.7 million & 43 million \\
\hline Total fertility rate & 3.9 & 4.4 & 3.9 \\
\hline Education (median schooling) & 7.3 years & 7.3 years & 7.6 years \\
\hline Literacy & $91.7 \%$ & $92.1 \%$ & $\mathbf{8 7 . 8} \%$ \\
\hline $\begin{array}{ll}\text { Media Access: } & \text { Newspaper } \\
& \text { TV } \\
& \text { Radio }\end{array}$ & $\begin{array}{c}2.8 \% \\
11.7 \% \\
56.6 \%\end{array}$ & $\begin{array}{l}15.2 \% \\
23.4 \% \\
73.3 \%\end{array}$ & $\begin{array}{l}17.9 \% \\
38.9 \% \\
69.7 \%\end{array}$ \\
\hline Currently employed* & $66.4 \%$ & $56.4 \%$ & $61.4 \%$ \\
\hline Top 3 employment types & $\begin{array}{c}\text { Agriculture, domestic } \\
\text { service, sales and services }\end{array}$ & $\begin{array}{c}\text { Agriculture, domestic service, } \\
\text { professional/technical/ } \\
\text { managerial }\end{array}$ & Same \\
\hline Age at first sex* & 17.6 years & 16.8 years & 18.0 years \\
\hline Age at first marriage* & 19.8 years & 19.2 years & 20.2 years \\
\hline Current FP use & $57.3 \%$ & $62.1 \%$ & $58.0 \%$ \\
\hline Received ANC & $97.5 \%$ & $96.4 \%$ & $95.5 \%$ \\
\hline Informed of pregnancy complications* & $59.7 \%$ & $62.4 \%$ & $58.4 \%$ \\
\hline BP Measured* & $94.8 \%$ & $83.8 \%$ & $94.0 \%$ \\
\hline Urine sample taken* & $91.5 \%$ & $80.0 \%$ & $88.8 \%$ \\
\hline Blood sample taken* & $96.8 \%$ & $92.7 \%$ & $96.0 \%$ \\
\hline \multicolumn{4}{|l|}{ Childbirth } \\
\hline Delivered with skilled attendant (facility) & $45.6 \%$ & $47.6 \%$ & $61.2 \%$ \\
\hline Delivered with TBA & $24.3 \%$ & $30.1 \%$ & $19.4 \%$ \\
\hline Delivered with help of relative/friend & $25.9 \%$ & $11.2 \%$ & $12.5 \%$ \\
\hline Received skilled PNC (within two days) * & $49.5 \%$ & $34.6 \%$ & $52.9 \%$ \\
\hline
\end{tabular}

*Statistics from the women's survey data from Kenya DHS 2014(7) and are disaggregated only at the regional level. 


\section{Sampling}

Respondents were purposively selected through key contacts and snowball sampling to include those knowledgeable about or had lived experienced PE/E. Sample sizes were pragmatically determined to capture representation for two counties, guided by theoretical saturation. National and county respondents were selected by their roles in maternal health policy and administration, with awareness of PE/E care; nationally, they included representatives from implementing partner organizations, health system and supply chain specialists, and RMNCH and community health program leaders. Two sub-counties with EmONC activities were identified in consultation with USAID and Community Health Management Teams (CHMTs). County stakeholders included CHMT representatives, sub-county health management teams (SCHMTs), and MNH champions. Facility assessments and provider interviews were conducted at county referral and sub-county hospitals $(n=2)$, health centers $(n=2)$ and dispensaries $(n=2)$, and communities surrounding health centers and dispensaries $(n=4)$ in each county. In Kitui County, two private hospitals were also included. Selected community health promoters and care providers $(n=15)$ included CHVs, TBAs, CHEWs, and community midwives, identified by county community units. Women who experienced PE/E in the 24 months preceding data collection were identified from maternity or ANC health records, and recruited by CHVs. FGD participants were sampled from selected facilities' communities and included adult men and women of reproductive age 18 years and older. MNH service data were extracted from records in 16 health facilities.

\section{Data collection}

The data collection activities for the study were:

1) Desk review of policies, guidelines, and strategies around maternal health with a focus on pre-eclampsia and eclampsia prevention and management. Seven documents were reviewed.

2) Eight FGDs with men and women: FGDs at community level were conducted with groups of married men and women with children (18 years and older) with at least one child, to understand PE/E perceptions and health seeking behaviors. In each county, four FGDs were conducted-two with men and two with women.

3) Six IDIs with policy makers at national, county and Sub County Levels: Information was collected to understand the supply chain, health systems, and other bottlenecks that prevent women from accessing or receiving timely ANC and delivery care.

4) Ninety-two IDIs with health providers and community level health Volunteers: This included doctors and nurses/midwives; CHEWS and CMWs; and TBAs and CHVs at county and sub-county hospitals, health centers, dispensaries, and within the community.

5) Sixteen IDIs with women who have experienced PE/E: In depth interviews were conducted with sampled of women who have experience PE/E to explore their stories and care-seeking pathways.

6) Review facility statistics at primary and secondary levels in $\mathbf{1 6}$ selected facilities: dispensaries, health centers, sub-county, and county hospitals: Aggregate maternal health statistics were extracted from facility registers as a proxy for facility burden and client flow.

\section{Data management and analysis}

Research assistants (RAs) were trained on research ethics and qualitative data collection methods in a five day workshop. The IDI and FGD guides were tested in a near peri-urban location in a similar context as the study counties; the guides were then discussed and revised for clarity, flow and comprehension. The interviews were conducted in Kiswahili or the local language (Kamba or Luyha) using digital audio recorders, uploaded and stored on password-protected computers in folders on a secure network. 
Data were transcribed in Kiswahili, Kamba, or Luyha and translated to English. A team of researchers read the transcripts and built analysis themes. Based on the themes, a code book was developed and applied to the data using NVivo version 10.18

\section{Results}

This section presents findings on bottlenecks and challenges that affect care access and service provision of prevention and management of pre-eclampsia. The themes presented include: 1) policy and programming environment around PE/E including knowledge of guidelines, protocols and job aids, 2) knowledge, perceptions and behaviors of ANC and delivery care seeking at the community level, 3) common contextual barriers such as financial, transport and distance that delay accessing services, 4) health systems and facility challenges including provider knowledge and resource capacity, 5) availability, use and supply of drugs $\left(\mathrm{MgSO}_{4}\right.$ and other antihypertensives) and equipment to manage PE/E, and 6) identified solutions.

\section{Policy and programming environment for pre-eclampsia and eclampsia}

Policy and programmatic gaps around PE/E are evident from our review of Kenya's first Confidential Report into Maternal Deaths, conducted by the $\mathrm{MoH}$ in 2017, showing that hypertensive disorders in pregnancy comprises the second leading cause (accounts for 20\%) of maternal deaths. Failure to recognize danger signs (12\%) and delay in deciding to refer (11\%) were the most frequently identified community factors associated with maternal deaths ${ }^{19}, 21$. Half $(50 \%)$ of all maternal deaths were among women who had been referred from another facility, mostly from level 4,5 , or 6 health facilities ${ }^{8}$.

A desk review and qualitative perspectives on existing maternal health policy guidelines and documents demonstrated moderate to high PE/E programming. Although the Strategy to Scale Up Effective Maternal and Newborn Health Interventions (2016-2018) and Kenya Reproductive, Maternal, Newborn, Child and Adolescent Health (RMNCAH) Investment Framework (2016) ${ }^{10}$ identify the use of $\mathrm{MgSO}_{4}$ as a highly effective in reducing adverse maternal outcomes associated with pre-eclampsia, they are silent on $\mathrm{MgSO}_{4}$ use in communities. The National Guidelines for Quality Obstetrics and Perinatal Care ${ }^{19}$, Focused Antenatal Care Training Package ${ }^{20}$, and Emergency Obstetric Care (EmOC) Training Curriculum ${ }^{21}$ devote sections to the diagnosis, clinical presentation, classification, predisposing factors, prevention, management and treatment including pre-referral treatment for PE/E. These documents, and the mother-baby booklet for ANC, report on provider and community members' roles in health education and counseling for danger signs during pregnancy, labor, and postnatal including PE/E. They concur on medical PE/E management in facilities. Job aids on $\mathrm{MgSO}_{4}$ dosage, administration, and danger signs exist but are not always available in all facilities; providers write them by hand, or do without. The 2010 Kenya Service Provision Assessment (KSPA) 22 showed 12 percent of facilities displaying essential maternal and neonatal guidelines for Kenya, 25 percent with EmOC guidelines, and 11 percent displaying EmOC visual job aids. The Community Midwifery Model aligns with the Kenya Health Policy (2014 to 2030) ${ }^{23}$, recognizing community service delivery to create demand and effectively provide specified services. The Community Midwifery Implementation Guidelines (2012) allow pre-referral management of PE/E including provision of $\mathrm{MgSO}_{4}{ }^{24}$.

Our qualitative study shows, while most national, county, and sub-county respondents report availability and use of PE/E policy guidelines and job aids, that some-like KSPA 2010-express doubts about their usability. Respondents said:

“We have maternal guidelines at the Reproductive Health Unit, a Community Health Strategy and policy guidelines, but they are rather unspecific to pre-eclampsia and eclampsia. The reproductive health guidelines are more clinical, they have job aids and algorithms for management of pre-eclampsia and eclampsia. If you go to the facilities, you will find them...hanged on walls, so they are there. But there is a difference between having guidelines and guidelines being used."

Respondent, national level 
“We have guidelines, policies, posters, even some friendly guidelines. They have been developed and put in most of the service areas and they are aimed at helping clients so for those who are very active they are likely to pick out some of these cases but still some fail on the same, but the guidelines are there."

SCHMT, Kakamega

"When you walk around you will see charts on the wall explaining how to deal with it, pre-eclampsia and eclampsia. It's something that let people know how to identify it and how to deal with it before someone else comes on board." hospital

Provider, Kakamega

Some respondents suggest that budgetary constraints and inadequate prioritization of MNH services by national and county governments lead to lack of access to critical documents and job aids and limits providers' useparticularly in rural health centers and dispensaries-and perpetuates information gaps in PE/E prevention, management, and referral. Despite lack of guidelines' accessibility, providers evince good comprehension of their content.

"When you go to the Ministry portal under 'download,' all these guidelines are available...As health workers, some of us might not know that they're available in the Ministry website...the other challenge would be in that of the internet accessibility, and also who pays for internet which is not highly reliable. As we talk, [internet's] down...Overall, l'd say they're not easily accessible from the facility level."

Provider, Kakamega PHC

"We have a protocol for pre-eclampsia and eclampsia. What you should do, how much of magnesium sulphate you should give as a loading dose. You also need a pump for a loading... and you are supposed to monitor in a woman who has eclampsia. We've done [protocols]; we have booklets and manuals to train people on the same."

Provider, Kakamega PHC

Policy implementation of CMWs' community management is described as ineffective by policymakers, program and county and sub-county managers, as well as communities. Respondents all suggest that $\mathrm{MgSO}_{4}$ was not being administered by CMWs, despite existing guidelines recommending the drug to be a part of the CMW's essential supply24. The major challenge was often due to lack of supplies reaching CMWs, preventing them from administering $\mathrm{MgSO}_{4}$ more frequently.

"For a midwife it is not a problem, but...you need to monitor blood pressure while using magnesium sulphate. The blood pressure can drop drastically...for qualified midwives I don't think there is any problem. But I don't think they have the drugs."

SCHMT, Kitui

A CMW who is permitted to give $\mathrm{MgSO}_{4}$, but who has never had the occasion to administer it, described her challenges with its administration:

"It is not easy to use because it is not like the common drugs, especially when dealing with [dosage] of intramuscular injections, but when you are giving IV infusion it is a bit easy."

CMW, Kitui

A few community members also suggested that CMWs should administer the drug-but with caution.

"I think they would need to be more careful with [use of $\mathrm{MgSO}_{4}$ at community level]. First of all, maybe they identify retired nurses who are within the community. That's the first step of taking precautions. Then identify retired medical practitioners, there could be even retired medical officers...care should be taken."

Male MNCH champion, Kakamega

\section{Pre-eclampsia and eclampsia knowledge, perceptions and care-seeking behaviors}

Women's ability to identify complications, myths and misconceptions, inadequate support from male partners and mothers in law, and gender and other norms related to health service access affect their PE/E knowledge, perceptions, and care seeking. Women with pre-eclampsia, their birth partners, as well as community members are described as lacking knowledge and ignoring danger signs such as swelling of the body, and sometimes, convulsions, as they consider them normal pregnancy experiences, unaware of the need for early intervention. When asked why women delay seeking care for complications, providers and some policymakers concur. 
"Ignorance... When they see they are swelling, they just think this is just normal and is because of the pregnancy. I think the community here has not understood the seriousness of high blood pressure in pregnancy and the need for seeking early intervention."

Provider, Kakamega hospital

“The knowledge of the community on pre-eclampsia and eclampsia is low... They don't understand what elevation in blood pressure in pregnancy means, what the possible complications could be. That's why sometimes you come across somebody who is on treatment, you talk to them about possibly admitting because maybe the blood pressure is quite elevated, and the patient would still decline admission, or request to be discharged home on medication."

SCHMT, Kakamega

A woman who had experienced PE/E, and her birth partner, seemed completely unaware of danger signs:

“At the beginning, apart from those other ailments, I used to have frequent roho inatingika [severe heart palpitations]. I would have [heart palpitations] continuously for about two hours, then they would stop, then they would start again, and then they would stop. Then my body felt very weak. It went on for one month...and I would tell my mother-in-law, "I feel here in my chest there is something that is really [palpitating], I don't know what it is.' At that time, I did not go to the hospital... Thereafter is when I started experiencing that weakness after the heart palpitations. I started becoming weak, my legs started swelling, I had headaches, dizzy spells, and I would have no strength in my body-if I was standing up, I would just collapse."

Pre-Eclampsia survivor, Kakamega

In contrast, a few knew that PE/E is dangerous and causes complications and death of mothers and babies. Men in an FGD observed:

"[I] am aware but I do not know much about it..."

Young man, FGD, Kakamega

"It's dangerous because when blood pressure is elevated, you could lose someone. They can die if not attended to quickly..."

Young man, FGD, Kakamega

"Both, the mother and the child..."

Young man, FGD, Kakamega

\section{Knowledge and antenatal care seeking}

ANC provides a platform for PE/E prevention, detection, and management. Interventions such as taking medical histories to identify risks and proactively manage women, educating them and their family members on danger signs, with BP and urine tests to detect PE/E, and management or referral as appropriate, are an important aspect of ANC services. KSPA 2010 showed that 96 percent of first ANC visit clients, nationally, had BP measurements, 91 percent had their urine tested, and 90 percent had blood testing for anemia. Of observed ANC consultations, only 35 percent of women were counseled on headache and blurred vision-danger signs for PE/E-32 percent for swelling of hands or face, and in only 18 percent of consultations did a provider use visual or job aids 22 .

National and county policymakers describe improved ANC attendance (i.e. at least one visit), but late (at 36 to 38 weeks), incomplete, or inconsistent ANC visits emerged as a major challenge with all respondents, suggesting undetected danger signs and maternal complications. Many respondents suggest that health education is critical for women to identify danger signs early to avoid negative pregnancy outcomes of PE/E.

“We've seen tremendous improvement especially in antenatal care, close to 100 percent come for antenatal care at least once... Many of them come late usually in the third trimester...Late for you to make any significant intervention that will sort out anything."

Respondent, national level

A CHMT member reported:

"Mothers come to us who have not been attending antenatal care clinic...[but] suffer from hypertension in pregnancy, we see mothers coming in with full blown Eclampsia....they are fitting, and they come here for the first time. As a result, in most cases we lose the baby...in some cases, we end up losing the mother when they come late."

CHMT, Kakamega 
Some community members suggest that access to ANC services has improved.

"Women can attend antenatal care more easily...we have health facilities nearby...Previously the problem was that we did not have health facilities nearby, but now, I don't think their problems are that serious because they attend ANC clinics when they are given appointments."

CHV, Kakamega

A similar sentiment was expressed by some providers:

"When you talk to them it is like it is not very important to them to attend the antenatal care visits. So, when they come for the first visit the antenatal care profile is done and if they are told your blood is well, the baby is well, and you have no problem they feel they are comfortable and they can carry the pregnancy to term... without realizing there are many challenges that can arise during pregnancy."

Provider, Kitui PHC

\section{Gender and social norms, and care-seeking behavior}

Many women reported delays in visiting a health facility after PE/E danger signs, leading to further complications. Unsupportive spouses and extended family members, especially mothers in law, and exposure to domestic violence during pregnancy, aggravated by spousal alcoholism, contribute to this delay. For some mothers, particularly younger ones, myths, cultural beliefs, and misconceptions about ANC services, $\mathrm{PE} / \mathrm{E}$, along with other illnesses, and delivery also influence familial decision-making.

"The biggest issue here is the level of information available at household level on maternal care...This affects referral services from level 1 to level 2 because most of the cases we see are delayed decision making. That's why issues on maternity become very complicated, and that's why we find quite a number not coming to the facility, and delivering at home, leading to complications." CHMT, Kakamega

"The other thing is there is a belief in the community traditional birth attendants. They believe if they deliver at her place she will be able to deliver the sex of the baby they want, that is either a boy or a girl, so they book the traditional birth attendant....to assist their delivery."

CMW, Kitui

In some instances, women do not attend complete ANC due to ignorance, shame or fear. One young woman described her pre-eclampsia experience and not attending ANC during pregnancy:

"During the first pregnancy...I was still a girl. I had just finished Form four and was ashamed to walk around. I didn't even know what was happening to me, so hid myself... that is why I [did not attend ANC]."

Pre-Eclampsia survivor, Kakamega

Providers in both counties suggest that birth partners' decisions influence PE/E prevention and management.

"I referred the lady. She was escorted by the mother in law...who was like the bread winner in that family. When she saw that I had referred her, she went outside, and the mother told her that it was nonsense and that they should go home...I looked for my patient, but I could find her, and they didn't have a phone. She disappeared and came back after a week with very high blood pressure."

Provider, Kitui PHC

\section{Lack of male involvement}

Some respondents report men as neglecting their responsibility of taking care of their families; and women incurring more stress, which they suggested pre-disposes them to PE/E. A general perception is that men do not offer support or show concern for women with pregnancy-related problems, including nutrition; men view any symptoms as normal and do not encourage women to seek health care services.

“There are some husbands who say that they don't see the need for the woman to go to seek health care services for such a problem because as far as they're concerned it is a normal thing. Some men tell the wife, 'Other women give birth without having to go to the hospital, why is your case different?'

...Pregnant woman is just being a bother, so this demoralizes them from seeking health care."

Older man, FGD, Kakamega 
"As pregnant women, when you share with your husband that you have been told not to do the heavy duties, he thinks you are pretending, so we suffer a lot. When you husband tells you that he doesn't have money to buy water and you need it to retain the baby, you just have to do it yourself."

Young woman, FGD, Kitui

Findings also suggest that men feel 'ashamed' or refuse to accompany pregnant wives for ANC. The inquisitiveness and queries of health workers-particularly "personal questions" and fear of being subjected to perceived mandatory HIV testing (HIV testing In Kenya is voluntary)-deters men from accompanying their wives.

"She just goes with her children...[laughter]"

Young man, FGD, Kakamega

"Because even mine tells me to accompany her...that she has been asked to come with me...I tell her I don't know where the health facility is? [laughter] It's a bit shameful." Young man, FGD, Kakamega

"Your income may be low, so your wife may not even have a decent dress to wear to the clinic...you feel ashamed to walk with her."

Young man, FGD, Kakamega

"When you go there, some of the questions they ask are too personal. You wonder if there is really any need to such questions...like, 'When did your wife conceive?' 'How are you taking care of her?' Such questions...those are obvious things. How am I to know the date?"

Older man, FGD, Kitui

"Then they will tell you both to go for [voluntary counseling and testing]."

Older man, FGD, Kitui

\section{Common barriers and delays}

Common problems in Kitui and Kakamega were explored, for understanding their maternal health contexts. In both counties, poverty, poor nutrition, and gender norms, among others, delay women from accessing services for PE/E prevention, detection, and management. Other barriers included transportation including distances to the health facilities and referrals.

\section{Financial and poverty barriers}

Respondents from all health care levels suggest that financial constraints and poverty, coupled with increased financial demands attributed to pregnancy, delay access to PE/E management and care. Poor pregnant women place the responsibility of meeting their family needs first, such as looking for water and food, limiting their time for seeking ANC services. In both counties, particularly in Kitui, pregnant women need to work to provide for the family, regardless of its toll on their maternal health (i.e. needing rest if experiencing pre-eclampsia).

"Some have to work too hard while pregnant. You find a pregnant woman having to fetch 20 jerrycans [containers] of water for someone to earn money. When you tell her that doing heavy work while pregnant is risky, she asks you what she will eat."

CMW, Kakamega

Women also lack money for transportation to health facilities and prescribed medicines that are unavailable at their health care facilities. Poverty and hunger deter care seeking during ANC and delivery.

"The first thing I can say is poverty is high. Despite the free maternity, we have those people who come from very far-sometimes they have no fare to take them to a health facility. You find them delivering at home...because of the poor economic status, some of them don't make it to the hospital so it becomes also a challenge for us."

Provider, Kakamega hospital

"If you are hungry you will not be able to go to the facility, you have not fed the whole day and then you are thinking of walking all the way to hospital and you are sick, you just prefer to stay at home."

Young woman, FGD, Kitui

Some mothers apparently still pay for selected services despite free maternity services. ANC costs excluded from free maternity services include referral transportation, laboratory tests, abdominal scans, antihypertensive drugs, and hospital admission fees. 
"Most want these free services sometimes which are not that free. Because we are told that maternity is free but when these women come we have things like the antenatal care profile, where they are required to pay for the lab services. It's not that free."

SCHMT, Kakamega

\section{Distance, mode of transportation, and referral barriers}

The two counties report notable improvements in building new facilities for reducing distances between facilities. Despite these efforts, distances to a functional facility are still a challenge. Many respondents describe high transportation expenses and security concerns, especially for services at night. Transportation challenges also lead to inconsistent or erratic ANC visits. In Kitui, distance was reported as a major barrier to CHVs' ability to locate and visit clients' houses, as many are far apart. Distance poses challenges during pregnancy and childbirth complications when referrals to advanced care are necessary, also affected by terrain, cost, and ambulance availability. Some pre-eclamptic mothers who intended to deliver in a hospital did not due to distance.

"Transportation, most of them come from rural areas and they find it difficult to come to the facility...They will tell you walking is difficult. They come from the interior areas, so you find them telling you that they did not come for this visit when I felt [pre-eclamptic symptoms] because I did not have transport fare."

Provider, Kakamega PHC

"The distance from where we reside to where we can get a vehicle is a two hour walk. When I started feeling contractions and the pain intensified, I knew I was about to give birth. At our rural home, we do a lot of manual work, so the labor pain is usually less as presumed. When mine started, I decided to search for a vehicle. The boda guys could not carry me in my condition. Since it was night time, I tried to be patient and wait for a vehicle as the pain intensified, but I could not and had the baby inside a church."

Pre-Eclampsia survivor, Kitui

Providers in remote areas seem to get frustrated with referral protocol in case of emergencies such as severe pre-eclampsia or eclampsia. At times, the only referral vehicle is unavailable or in a different county altogether. The referral process is also complex, with multiple layers of authority, making it cumbersome and causing delays (particularly in rural areas) in urgent care situations.

"If we get an emergency requiring referral, we call to the headquarters in [facility] to get an ambulance here [health center]. That road is several kilometers and the [bad] terrain...the ambulance may not be there, it might have gone to [hospital] or some other place, so it takes hours to assist that patient. Finally, if it gets here; say the patient arrived at 9pm and you are transporting her at 3am...count the hours lost. You can lose either the baby or the mother in cases of emergency." Provider, Kitui PHC

"One of the challenges is the referral system... When you have an emergency, especially in the labor ward [of a health center]. You call the Ambulance...you are told the ambulances are in [counties]. You are desperate..."

Provider, Kakamega

"The process is long and complicated... When you call the DPHN or the SCPHN you get that some of them don't respond to the calls. Sometimes their phone is off so there is no one to organize for you to go to [hospital]. Other times you reach them and are told the ambulance is elsewhere...and the mother in labor has complications."

Provider, Kitui PHC

\section{Health system and facility challenges}

Facility factors, such staffing and provider knowledge and practice, were found to influence PE/E management and women's care experiences.

\section{Staffing and experience of care}

Budget constraints were identified as challenges for $\mathrm{MNH}$ and PE/E care in both counties, leading to increased workloads and understaffing, compromising the quality of services and mothers' experience of care. Women experience long waits for ANC and related services, which discourage some from obtaining required laboratory tests or future follow up visits. 
"We have understaffing, the workload pressures us. Sometimes you compromise the quality of service you are giving because of the workload...[Women] queue for so many hours to see the health care giver because there is only one, and may [instead] decide to stay at home...You are fatigued and unable to explain to a patient her examinations-how it progresses from mild to severe pre-eclampsia and eclampsia."

Provider, Kitui hospital

"We have a severe shortage of staffing... which affects what we are trying to do...the major thing again is to employ despite the budgetary constraints. We are in the process of employing new nurses."

CHMT, Kitui

Staff retention and attrition were cited as factors affecting service delivery. In some instances, counties lack capacity (both staff and infrastructure) to conduct C/S to save mothers' lives, in cases of severe PE/E. This was more pronounced in Kitui County.

"The other challenge is the staff turnover, where we have the retirement, and the transfers and even the inter-ward change overs. You can have a midwife who has been in maternity with so much skill, and they want to exit to another place. You [then] bring in someone lacking the proper skill..."

Provider, Kakamega hospital

"We have hospitals that are not well developed... the only hospitals within the county that are able to do a caesarean section are only two, the [level 4] and [level 5]. The other sub-district hospitals, they are not able to do a Caesarian section."

Provider, Kitui PHC

The desk review concurs on infrastructural challenges: KSPA 2010 showed 65 percent of facilities with running water, 32 percent with soap or disinfectant, and 71 percent with latex gloves-all necessary for examining clients-36 percent had comprehensive infrastructure for delivery and 79 percent had a delivery bed 22 . A study in a tertiary hospital in Kenya showed that women admitted with eclampsia are 10 times more likely to die during childbirth than women without eclampsia (OR 10.9, 95\% Cl 3.7-31.9, $p<0.0001)^{25}$. According to the Saving Mothers' Lives confidential Enquiry into Maternal Deaths in Kenya 2017, although health workforce factors associated with maternal deaths primarily report provider-centered components such as delayed treatment start (33\%), inadequate clinical skills (29\%), and inadequate monitoring (25\%), infrastructural problems and lack of operation equipment contributed to 10 percent and 13 percent of maternal deaths, respectively8.

\section{Provider knowledge, skills and confidence in use of $\mathrm{MgSO}_{4}$}

Appropriate $\mathrm{MgSO}_{4}$ administration in $\mathrm{PE} / \mathrm{E}$ management is critically important in reducing maternal and neonatal complications. Some providers are unsure about the recommended $\mathrm{MgSO}_{4}$ regimen (Box 1 ) even though they are quite conversant with nursing care PE/E management, such as need for monitoring vital signs and urine output.

"You give a loading dose [of $\mathrm{MgSO}_{4}$ ] first-intravenous loading dose of four grams of 20 percent then you give 10 grams of 50 percent intramuscular and the intramuscular you give each five $\mathrm{ml}$, diluting with two percent of liquid chemicals. It is painful and then maintenance dose I think one gram of 20 percent hourly... is it hourly or four hourly? That one I am not sure. Then you monitor the blood pressure the fetal heart because a mother with pre-eclampsia does not always need a Caesarian section...We monitor every half hour to check the pressure is stable."

Provider, Kakamega PHC

"The challenge, I would say, is administering $\left[\mathrm{MgSO}_{4}\right]$...connecting the practice with the knowledge on the actual administration sometimes is a problem. I think it's demystifying and having the right [dosage] and having that capacity...sometimes people avoid what they are not sure about. So, it's important I think for that to be done so that we capacity build them on how they are supposed to administer."

CHMT, Kakamega 


\section{Box $1-\mathrm{MgSO}_{4}$ regimen in Kenya}

Loading Dose: Magnesium sulphate 20\% Solution, $4 \mathrm{~g}$ IV over 5 minutes. Follow promptly with $10 \mathrm{~g}$ of $50 \%$ magnesium sulphate solution, $5 \mathrm{~g}$ in each buttock as deep IM injection with $1 \mathrm{~mL}$ of $2 \%$ lignocaine in the same syringe. If convulsions occur after 15 minutes, give $2 \mathrm{~g}$ magnesium sulphate ( $50 \%$ solution) IV over 5 minutes.

Maintenance Dose: Give $5 \mathrm{~g}$ magnesium sulphate (50\% solution) $+1 \mathrm{~mL}$ lignocaine 2\% IM every 4 hours into alternate buttocks. Continue treatment with magnesium sulphate for 24 hours after delivery or the last convulsion, whichever occurs last. If $50 \%$ solution is not available, give $1 \mathrm{~g}$ of $20 \%$ magnesium sulphate solution IV every hour by continuous infusion.

"There's a lot of fear about magnesium sulphate, and they fear a lot about toxicity and yet we know the margin of it are actually quite good...Simple things-being able to monitor as you're administering, breathing, patella reflexes and level of consciousness... There's more fear for the risk of toxicity than to the benefit that it actually provides."

Respondent, national level

The lack of confidence with $\mathrm{MgSO}_{4}$ reflects the broader deficiency in provider skills in managing PE/E, which reflects insufficient practical training and practice. Although many surveyed providers report that health workers at level 4, 5, and 6 hospitals possess the necessary skills and knowledge for taking BP and test urine, only some at lower level facilities (health centers and dispensaries) reported confidence in these techniques and making appropriate referrals.

\section{Availability of $\mathrm{MgSO}_{4}$, antihypertensive drugs and essential equipment}

\section{$\mathrm{MgSO}_{4}$ and antihypertensive drugs}

Public health facilities in both counties depend mainly on the Kenya Medical Supplies Authority (KEMSA) for essential MNH drugs, commodities, and supplies, whereby counties place routine orders and pay on delivery. The Mission for Essential Drugs Supply (MEDS), a Christian non-profit, is the primary supplier of private and faithbased health facilities. While $\mathrm{MgSO}_{4}$ was reported available through KEMSA and county stores by national program and policymakers CHMT and SCHMT, some providers reported it not always available in level 2 and 3 (health centers, dispensaries) facilities. There are frequent stock outs of antihypertensive drugs such as alpha methyldopa, nifedipine, and labetalol. Counties procure drugs privately (as opposed to through KEMSA). Due to competing financial requirements in each county, these drugs are not usually prioritized, shifting cost and purchasing burdens on women suffering from pre-eclampsia, and their families.

"County budgets are limited so they prefer to give priority to other commodities such as the antibiotics and pain killers. The patients have to look for other drugs, which are considered secondary."

Respondent, national level

"Availability is a bit of challenge. There is not that steady supply. We see in some of the facilities there is not a steady supply of calcium gluconate, the antidote for magnesium sulphate, and the antihypertensive drugs are erratic. There are many issues; mostly right now with this devolution, with counties doing their procurement of commodities, you get either they are not able to pay up KEMSA in good time or KEMSA holds back until their cash is paid...It cuts across all drugs."

Respondent, national level

Kakamega reports consistent $\mathrm{MgSO}_{4}$ supply, while Kitui describes an interrupted supply chain. Both counties report stock outs for antihypertensive drugs.

“[ $\left.\mathrm{MgSO}_{4}\right]$ is available in our county, but I don't know about other counties. I now know that KEMSA deals with counties as individuals and there are counties which do not promptly procure, lack certain drugs. Since devolution, our county has been requesting for the drugs in good time and promptly paying for these essential commodities."

CHMT, Kakamega 
"The other challenge is the delayed release of funds from the national to county government-this is the money used to buy drugs. When the counties have not received money from the national government, KEMSA does not deliver drugs and we end up with stock outs. When there is no money to pay for drugs...many patients go without them."

CHMT, Kitui

Providers and community members also report short supply or stock outs of antihypertensive drugs for women experiencing pre-eclampsia and other hypertensive diseases in pregnancy. Stock outs and under-staffing in rural facilities-particularly health centers-further delays women from remote areas who experience pre-eclampsia; often these women face concurrent contextual barriers (e.g. poverty) previously described.

"[Drugs] are available on and off and so sometimes you are told to go and buy...If you come and you don't get the drugs that you were prescribed, and you don't have money to go to [hospital], [health center] has become a nightmare, because the woman is sick and need the drugs, you do not get them."

Community MNCH champion, Kitui

"The dispensaries in our locality have no [antihypertensives]...Many times, I am forced to go a private hospital and going there is Khs 300 on the motor bike. Going to [health center] you can miss the doctor or the drugs...So instead of wasting time, you go to [hospital] and get treated then come back."

Pre-Eclampsia survivor, Kitui

"Sometimes we observe this mother has preeclampsia and maybe the hospital or facility does not have those drugs. We tell the mother, 'You go and buy the drugs.' When the mother reaches home, she may not have the money and be able to buy the drugs."

Provider, Kakamega

\section{Equipment and supplies for BP and urine testing}

Some facilities, including referral hospitals (county and sub-county), did not have functional BP machines or urine dipsticks. Providers who lack BP machines have limited routine practice for measuring BP and lose these skills. Supply shortages were more pronounced in Kakamega.

"Most health facilities, especially level 2, do not have the capacity to do urinalysis to confirm whether there are proteins in urine in mothers whose blood pressure is elevated. Also, some of the staff in the rural health facilities are unable to pick out the elevation in blood pressure because either they don't routinely take the blood pressures of the patients or [the facility] might be missing a blood pressure machine."

SCHMT, Kakamega

"Sometimes we do not have enough equipment. Maybe we have only one blood pressure machine... when it has a mechanical problem, we do not have any."

Provider, Kakamega

Lack of adequate equipment and supplies to allow providers to diagnose PE/E during ANC in a timely way is compounded by a lack of facility infrastructure to effectively manage a premature baby-a common consequence of $\mathrm{PE} / \mathrm{E}$.

“We lack equipment to keep babies in all facilities...we don't have wrappers to dry the babies...Not all our facilities have resuscitators and Ambu bags for neonatal resuscitation...some don't have the penguin sucker to make sure the airway is clear."

CHMT, Kakamega

\section{Solutions to identified bottlenecks and challenges}

National, county, and sub-county facility and community respondents suggested ways to overcome these health system and community bottlenecks that affect use of life-saving interventions for PE/E prevention and management. Although most respondents observed that guidelines, protocols, and job aids exist, they also suggest a need-in response to the de-centralized system-for national support to counties to ensure these guidelines reach their intended places of use, including rural health facilities (levels 2 and 3 ).

"At [national] level, being able to improve availability of these guidelines and policies and job aids at the county levels. You see now when devolution came, we are no longer doing the printing. The counties are the ones who are supposed to print. Our current mandate is to avail the information in e-copy, and then they print."

Respondent, national level 
There is need to improve information, education and communication (IEC) on danger signs in communities along with provider knowledge, skills, and confidence in BP measurement, pre-eclampsia diagnosis, $\mathrm{MgSO}_{4}$ administration, and appropriate referral.

"Providers need more obstetric emergency training...The challenge has been that [PE/E] are rare so we keep forgetting...It is good that all staff be trained in case of emergency; if you are eight nurses in a facility, all should be trained."

Provider, Kakamega PHC

"Government should have people who educate the community on high blood pressure so that when one experiences the symptoms they will go to the facility for treatment then it will be easy to treat high blood pressure."

Young MNCH champion, Kitui

"To deal with pre-eclampsia and eclampsia, we should intensify education to the communities so that women are made aware of what it is. Signs, symptoms, what should be done. We can also engage our communities by having dialogues, even involving our husbands, men, and decision makers around maternal child health..."

SCHMT, Kakamega

Strengthening national and county coordination and accountability of maternal health services was recommended, including enhancing supply and equipment procurement, which was described as an area that needs to be strengthened to improve quality of maternal health and PE/E care-specifically improving county capacities to order drugs based on actual need and timely payment. Additional oversight is seen as necessary to ensure undue burdens are not placed on facilities, women, and communities to compensate for supply chain gaps.

"To quantify the amount of magnesium sulphate or the essential drugs needed would be a game changer in terms of increasing timely availability and reducing wastage...The reproductive health unit or county governments need to more prepared [in this process]... We have a national essential medicines committee and list [ 200 items]; they're able to prioritize and say what is needed...We cannot fund all of them and prioritize funds..."

Respondent, national level

"Drugs are more available now than during [pre-devolution]."

SCHMT, Kakamega

“You get stethoscopes or blood pressure machines that providers can't operate or are of poor quality. Some supplies received are of good quality and kept in stores if not in use... if not required, re-distribute them to other facilities where they can be used."

Respondent, national level

Some respondents-specifically providers and community health administrators-recommend recruiting staff for lower level facilities and deploying trainers to address staff shortages and improve PE/E management, in part to redistribute providers and avoid perceived complexity in referrals, but also to build capacities of existing nurses and midwives in lower level facilities to appropriately diagnose, manage, and refer for PE/E (based on national protocols). Others felt that some providers at lower level facilities are unable to offer pre-referral treatment to patients with $\mathrm{PE} / \mathrm{E}$, despite requisite training. This treatment delay is amplified by the complexity in referrals and distances to facilities.

"To improve these services, we need to put more staff in the periphery, like now we have the sub-county facilities with theaters and wards nearer to the communities. We can improve the accessibility because if we only have one facility for the whole of Kitui region, then it means that people have to come from far places, but when we put them in those closer facilities since [PE/E] is a very sensitive condition that is handled by the medical personnel in those facilities, which need close monitoring."

CHMT, Kitui

"We are trying to make health workers be aware that pre-eclampsia and eclampsia...these antenatal mothers can have $[\mathrm{PE} / \mathrm{E}]$ as they come to us. And it needs immediate care...Stocking $\left[\mathrm{MgSO}_{4}\right]$ within the antenatal care facility, so when they get a patient with the elevated blood pressure, they can start treatment there and not waste time in trying to refer her to go to the maternity area."

Respondent, national level 


\section{Service statistics from selected health facilities}

Sample service delivery statistics drew from 16 facilities ( 7 in Kakamega and 9 in Kitui) that included dispensaries $(n=2)$, health centers $(n=5)$, sub-county hospitals $(n=7)$, and county referral hospitals $(n=2)$. These facilities reported 9,415 first ANC visits per year, 5,426 fourth ANC visits per year, and 11,835 skilled deliveries per year (9,531 of which occurred in the hospital sub-sample). In aggregate, facility registers documented 2,425 C/S's a year and 2,251 at hospitals, suggesting a C/S rate of over 20 percent. Hypertension in pregnancy, particularly cases of PE/E were likely under-reported in PHC registers in both counties; an average of 111 cases annually were documented in the 16 study sites (mostly at sub-county and county referral hospitals, except for one health center in Kitui) compared to 219 cases for both counties and 4,944 cases nationally in DHIS 2 for the same period. These statistics are subject to under-reporting, inflating the $\mathrm{C} / \mathrm{S}$ rate, because of missing data from the eight months of provider strikes during the two and half year period. We were thus unable to fully describe patient flow, although at health centers and dispensaries pre-eclampsia is rarely documented by providerspossibly as result of lack of knowledge on diagnostics, lack of BP measurement apparatuses, or a function of its rarity as a condition.

\section{Discussion}

This study sought to explore barriers, bottlenecks, and opportunities to effective implementation of life-saving interventions for PE/E prevention and management. Our study reveals multi-level health systems challenges leading to low quality of ANC and PNC, and under-utilization of EmONC, services for preventing and managing $\mathrm{PE} / \mathrm{E}$.

\section{Policy programming environment}

Kenya has an amenable policy environment that includes policy documents that clearly outline prevention, management, and even its cost. Implementation largely relies on the governance environment, however, and Kenya's relatively new devolved government structure 26 mandates county governments deliver health services and implement health programs ${ }^{27}$. While both the national and county governments continue to improve mechanisms for effective and efficient health services and programs, recent studies show inadequate coordination between them for provision of $\mathrm{MNH}$ care including $\mathrm{PE} / \mathrm{E}^{28,29}$. The success of devolution heavily relies on good political will at all levels of Kenya's government, with a critical need to reduce duplication of roles and waste, and optimize resource utilization $30,31,32$.

Quality of maternal health care is often seen as an indicator of how well a health system functions-Findings from this study suggest several policy and implementation gaps or bottlenecks that need to be addressed. Neither study county was able to adequately forecast and procure drugs, supplies and commodities, and the national government delayed transfer of funds to the counties to facilitate county operations.

There are insufficient resources to support effective implementation of guidelines for anticonvulsants, antihypertensive drugs, and commodities for adequate diagnosis (BP machines and urine dip sticks) and referral strategies. Community Midwifery Implementation Guidelines ${ }^{19}$ allow community midwives to obtain $\mathrm{MgSO}_{4}$ supplies from their nearest facility, but CMWs interviewed did not have the drugs or supplies, even when they were available at facilities, seeming to suggest that CMWs are not fully prepared nor motivated to handle obstetric emergencies such as PE/E, despite policy. A 2013 study in western Kenya found that CMWs faced challenges with supervision, obtaining pay for work and concomitant insecurity, and were thus less effective in delivery of services than the policy intends ${ }^{33}$.

2 Kenya Health Information System dhis2 database: https://hiskenya.org/dhis 
The study also finds that policy documents, training materials, and job aids are not available at some health facilities, especially rural facilities, and IEC materials are rarely available in communities. The national government continues to print limited numbers of policy and training documents as well as IEC materials, while county governments also print the same documents. Counties report limited funds to print and distribute these IEC materials, and it is not clear whether counties see the need to print them if receive them from national supply.

\section{Common context barriers and delays}

\section{Knowledge and practice of providers}

Some providers lack knowledge of $\mathrm{PE} / \mathrm{E}$ management including $\mathrm{MgSO}_{4}$ dosage and administration. Respondents also expressed lack of confidence or perceived fear of $\mathrm{MgSO}_{4}$ toxicity that limits its use, particularly among providers in dispensaries and health centers. EmONC training in both counties mainly targets providers in hospitals, excluding providers at PHC facilities: This could explain the knowledge and skills gaps observed in our PHC provider sample, where those providers were reported to prefer other anticonvulsants such as valium even when $\mathrm{MgSO}_{4}$ is available. Our findings resonate with another study in Kenya showing gaps in provision of parenteral anticonvulsant, where 75 percent and 52 percent of providers reported administering injectable diazepam and $\mathrm{MgSO}_{4}$, respectively22. Other studies concur with low provider competence and confidence in $\mathrm{MgSO}_{4}$ use in PE/E management 5,34,35. Staff are either reluctant to use it or administer it inconsistently with current WHO recommendations $6,36,37$.

High provider attrition and redeployment affects practice and results, due to repeated retraining. Innovative MNH training approaches, especially with high staff turnover and need re-train staff on site, have been proven to work $39,40,41$. Evidence shows that PHC workers, with training, can offer $\mathrm{MgSO}_{4}$, especially if supported with functional referral systems ${ }^{38}$. Provider knowledge, competence, and confidence in managing PE/E can achieved be through such training approaches, and supportive supervision, for both lower and higher level facilities.

\section{Community knowledge}

There is low community awareness of danger signs in pregnancy. Women who had experienced PE/E, as well as community members often normalize symptoms and delay care seeking for ANC and delivery. Although KDHS 2014 shows increased ANC, less than 60 percent of women in the two study counties said they were informed about danger signs and complications during pregnancy at ANC visits ${ }^{7}$. Given the direct influence maternal health knowledge has on care seeking behavior, it is critical to strengthen CHVs' performance and guide them on appropriate actions after identifying maternal danger signs and complications so they are more effective in referring women-in addition to their role in improving general maternal health awareness ${ }^{42}$.

Women delay seeking heath care services as a consequence of various intersections of socio-economic and gender factors, as seen in the findings related to decision-making influences-by competing household duties, income generation activities, presence or lack of male partner support, and PE/E myths and stereotypes. Gender norms and negative stereotypes, such as women's limited role in decision-making for her health, family finances, provision of family needs and household duties, discourage facility-based care-seeking during pregnancy and resonate with other research in Kenya, as well as globally43,44,45. Additionally, gendered effects and the confluence of multiple social normative factors may be even more influential in younger women ${ }^{46}$. As noted in our findings, young pregnant women in Kitui and Kakamega-particularly students-hesitated to attend ANC due to shame or lack of knowledge. Many women, including PE/E survivors, did not seek skilled delivery care and PNC services because they felt it was not necessary, or of low quality. Health-seeking behavior is affected by various factors, among them poverty 47,48 , knowledge, or lack thereof, of danger signs, perceived quality of importance of care, and social support structures ${ }^{49,44,50}$. 
Access to care and referral is also hampered by transportation-distances, modes, costs, and availability-from rural facilities to county referral hospitals. Communication channels requesting ambulances at rural health facilities frustrate providers and community members. In 2010 KSPA ${ }^{17}$ indicated an inadequate referral system: Then only 32 percent of health facilities had an ambulance for referral and 46 percent of all facilities surveyed had providers working 24 hours.

Although referral and transportation barriers are common in the two counties, they are more profound in Kitui. Evidence suggests that, while women make an effort to seek services for maternal complications, use of PNC and ANC services decreases if they have to travel distances greater than four kilometers ${ }^{51}$. Lack of physical access to facilities, due to insufficient numbers of facilities, distances to them, and inadequate transportation infrastructure including ambulances, limit utilization of maternal health services ${ }^{52,53}$.

\section{Availability of drugs and essential supplies}

Kenya embraces use of $\mathrm{MgSO}_{4}$, at all levels of health care: It has been on the national EML as a key commodity for emergency maternal health services since 2002. The policy has yet to be fully operationalized, however, as it is still not available at lower levels of the health system, at level 2 and 3 facilities, nor through CMWs in communities. Research from other countries shows that providing this life-saving drug at PHCs reduces deaths and morbidity associated with $\mathrm{PE} / \mathrm{E}^{53}$. Although $\mathrm{MgSO}_{4}$ is reported as largely available in Kenya, antihypertensive drugs experience considerable stock outs, affecting facilities' abilities to manage pre-eclampsia.

Kitui and Kakamega counties rely on KEMSA and MEDS for their drugs, equipment, supplies, and commodities. Both supply chains have clear guidelines on forecasting, ordering, and procuring drugs, but some facilities fail to forecast well. This leads, in some instances, to lack of timely payments, due to inadequate resources, or lack of prioritization for specified $\mathrm{MNH}$ commodities for $\mathrm{PE} / \mathrm{E}$, or poor coordination between the national and county governments that occasionally delay funds disbursement, resulting in stock outs in $\mathrm{MgSO}_{4}$, antihypertensive drugs, urine dip sticks, as well as BP equipment. The 2010 KSPA $^{17}$ showed 97 percent of health facilities with both diazepam and $\mathrm{MgSO}_{4}$ for eclampsia management, and 23 percent with other hypertensive drugs (hydralazine, nifedipine, labetalol, alpha methyldopa), and 89 percent of facilities had a BP apparatus, 91 percent had intravenous fluids, and 38 percent had capacity to test urine for protein.

Lack of functional equipment (e.g. BP machines) and human resources also merit attention. Studies show that lack of equipment and supplies limits access to care ${ }^{54,55}$.

\section{Recommendations}

Strengthen capacity for improved coordination and oversight between national and county governments to enhance continuous supply of commodities, equipment, and supplies to leverage resources for maternal health, specifically PE/E services. This recommendation reflects the challenges of procurement and costs to facilities and women themselves limiting access to antihypertensive drugs. One strategy is to encourage use of KEMSA's mechanisms and follow up regularly through CHMT meetings on any instances of county or national delays to mitigate adverse effects of devolution.

Build confidence of providers at lower level facilities for PE/E prevention and management, particularly use of $\mathrm{MgSO}_{4}$. This involves refresher EmONC trainings focusing on PE/E diagnosis-including BP measurement, urinalysis, diagnosis and referral, and administration of $\mathrm{MgSO}_{4}$. We also recommend a deliberate mentoring approach effective in other contexts, for nurses, midwives, and CHEWs to better recognize and manage PE/E in level 2 and 3 health facilities (dispensaries and health centers), along with CMWs within communities. We recommend an implementation research study on other community interventions to assess CHV capacity and willingness (given their unpaid status) to use BP machines to measure BP, and refer promptly to facilities for further care; this would strengthen the administration of $\mathrm{MgSO}_{4}$ as a life-saving commodity in Kenya. 
Develop, test, and support innovative ways to educate community members on PE/E danger signs and the need for prompt care. Specifically, we recommend community training platforms and dialogues, as well as media platforms. Radio messages incorporated within regular programming (in each county's local language) would be particularly useful to remind women to consult, reflect, and act upon danger signs, in addition to other key health messages in their mother-baby booklet provided at ANC, which all women receive but often forgot to check. ANC booklets for all expectant mothers, that include PE/E danger signs and symptoms, and encourage mothers to ask providers about these conditions, should be improved. Kenya has initiated group ANC to improve ANC services in selected counties ${ }^{56}$, and as scale up begins, the platform can be further strengthened with clients' education on pregnancy complications including PE/E.

Improve community and rural facility referrals for patients with maternal complications. This recommendation stems from inefficiencies observed in referral and transportation. Limited vehicle availability and the complex process of relying on a $\mathrm{RH}$ coordinator and ambulances to respond in an emergency is problematic in urgent $\mathrm{PE} / \mathrm{E}$ situations. There is a need to enhance communication and responses between community and lower level facilities and referral sites. Better understanding and incorporation of CHVs, to serve as liaisons, is critical in this process.

Our study corresponds with others for the need to bolster staffing of skilled providers at lower level facilities, as well as building capacities of all health facility staff (at all levels) for PE/E information and communication $35,51,52$. Implementation research on $\mathrm{PE} / \mathrm{E}$ service provision within an evolving, decentralized system merits further testing to better understand how policy implementation in such a context, and build evidence for relevant stakeholders. This research can help further build evidence on how best to reduce barriers to PE/E prevention and management in Kenya. 


\section{References}

1. Abalos E, Cuesta C, Carroli G, Qureshi Z, Widmer M, Vogel JP, et al. Pre-eclampsia, eclampsia and adverse maternal and perinatal outcomes: a secondary analysis of the World Health Organization Multicountry Survey on Maternal and Newborn Health. BJOG Int J Obstet Gynaecol. 2014 Mar 18;121(s1):14-24.

2. Berzan E, Doyle R, Brown CM. Treatment of Preeclampsia: Current Approach and Future Perspectives. Curr Hypertens Rep. 2014 Sep 1;16(9):473.

3. Jammeh A, Sundby J, Vangen S. Barriers to Emergency Obstetric Care Services in Perinatal Deaths in Rural Gambia: A Qualitative In-Depth Interview Study. ISRN Obstet Gynecol. 2011;2011:1-10.

4. Hurst TE, Semrau K, Patna M, Gawande A, Hirschhorn LR. Demand-side interventions for maternal care: evidence of more use, not better outcomes. BMC Pregnancy Childbirth. 2015 Nov 13;15:297.

5. Obare, F, W Liambila, D Okoro, R Ayisi, S Ochola. Factors contributing to maternal mortality in relatively resource-endowed urban contexts of developing countries: the case of Nairobi, Kenya. Afr Popul Stud. 2016; 30(3). http://aps.journals.ac.za/pub/article/view/922

6. Long, Q, OT Oladapo, S Leathersich, JP Vogel, G Carroli, P Lumbiganon et al. Clinical practice patterns on the use of magnesium sulphate for treatment of pre-eclampsia and eclampsia: a multi-country survey. BJOG Int J Obstet Gynaecol. 2016 Nov 24;124(12):1883-90.

7. ICF Internation. Kenya Demographic and Health Survey 2014. Rockville, MD, USA: Kenya National Bureau of Statistics, Ministry of Health/Kenya, National AIDS Control Council/Kenya, Kenya Medical Research Institute, National Council for Population and Development/Kenya, and ICF International. 2015 Mar.

8. Ministry of Health Kenya. Saving Mothers Lives 2017. First Confidential Report into Maternal Deaths in Kenya. 2017.

9. Population council. The Safe Motherhood Demonstration Project, Kenya - Ministry of Health, University of Nairobi and Population Council, Introducing Magnesium Sulphate for the Management of Pregnancy Induced Hypertension. April, 2005, Safe Motherhood Policy Alert. 2005. Policy brief.

10. Ministry of Health. Strategy to scale up effective Maternal and Newborn Health interventions (20162018),Nairobi, Kenya. Nairobi; 2012.

11. Ministry of Health. Kenya Reproductive, Maternal, Newborn, Child and Adolescent Health (RMNCAH) Investment Framework, Ministry of Health, Government of Kenya, January 31, 2016.

12. Omboga Omweri. Use of National Guidelines in Management of Severe Preeclampsia/Eclampsia at Garissa Provincial General Hospital: A Cohort Study. University of Nairobi; 2016. http://obsgyn.uonbi.ac.ke/sites

13. Yin, R.K. Case study research: Design and method [Internet]. 3rd edition. Thousand Oaks, CA: Sage; 2003. https://books.google.co.ke/books/about/Case Study Research.html

14. Republic of Kenya. MDG Acceleration Framework and Action Plan for Kenya. New York; 2014.

15. Jhpiego. www.jhpiego.org/where-we-work/kenya

16. UNICEF. Annual Report 2016 Kenya. www.unicef.org/about/annualreport/files/Kenya_2016_COAR.pdf

17. Mwangi, A and C Warren. Taking Critical Services to the Home: Scaling-up Home-based Maternal and Postnatal Care, including Family Planning, through Community Midwifery in Kenya. 2008.

18. Castleberry, A. NVivo 10 [software program] Version 10. QSR International; 2012. | American Journal of Pharmaceutical Education. www.ajpe.org/doi/full/10.5688/ajpe78125 
19. Ministry of Health, Kenya. Policy guidelines reviewed are National Guidelines for Quality Obstetrics and Perinatal Care, Ministry of Public Health and sanitation and Ministry of Public services, 2012, Republic of Kenya. Nairobi.

20. Ministry of Health, Republic of Kenya. Focused Antenatal training package. 2014.

21. Ministry of Health, Republic of Kenya. Emergency Obstetric Care $(\mathrm{EmOC})$ training package , MoH, Republic of Kenya. 2016.

22. Kenya National Bureau of Statistics (KNBS) [Kenya ], ICF Macro. 2011. National Coordinating Agency for Population and Development (NCAPD) [Kenya ], Ministry of. Medical Services (MOMS) [Kenya], Ministry of Public Health and Sanitation (MOPHS) [Kenya],. Kenya National Bureau of Statistics (KNBS) [Kenya ], ICF Macro. 2011. Kenya Service Provision. Assessment Survey 2010. Nairobi. https://dhsprogram.com/pubs/pdf/SPA17/SPA17.pdf

23. Ministry of Health, Republic of Kenya. Kenya Health Policy (2012 to 2030). 2012.

24. Ministry of Health, Kenya. Community Midwifery Services in Kenya. Implementation Guidelines. Second Ed. 2012. www.medbox.org/community-midwifery-services-in-kenya-implementation-guidelines

25. Yego et al. 2014. Risk factors for maternal mortality in a Tertiary Hospital in Kenya: a case control study I BMC Pregnancy and Childbirth. https://bmcpregnancychildbirth.biomedcentral.com/articles/10.1186/1471-2393-14-38

26. Ministry of Devolution and Planning. Policy on Devolved System of Government. 2016.

27. Ministry of Health. Kenya Health Policy 2014-2030. Towards attaining the highest standard of health, Ministry of Health. 2014.

28. Tsofa, B.et al. How does decentralisation affect health sector planning and financial management? a case study of early effects of devolution in Kilifi County, Kenya | International Journal for Equity in Health. 2017 https://equityhealthj.biomedcentral.com/articles/10.1186/s12939-017-0649-0

29. Kanyinga, K. Devolution and the New Politics of Development in Kenya | African Studies Review | Cambridge Core. 2016. www.cambridge.org/core/journals/african-studies-review/article/divclasstitledevolution-and-the-new-politics-of-development-inkenyadiv/F02ED6A5E87D9B060FE1FB5E689633A0

30. Lipsky, A, A Mulaki, T Williamson, Z Sullivan. Political Will for Health System Devolution in Kenya: Insights from Three Countie. Policy brief. 2015.

31. D'Arcy, M and A Cornell. Devolution and corruption in Kenya: Everyone's turn to eat? Afr Aff. 2016 Apr 1;115(459):246-73.

32. World Bank. Improving Health Outcomes and Services for Kenyans. Sustainable Institutions and Financing for Universal Health Coverage Kenya Health Policy Forum 18-20 March 2014, Windsor Hotel. Nairobi. http://documents.worldbank.org

33. Liambila, W, F Obare, C Undie, H Birungi, SN Kuria, RW Muia et al. The community midwifery model in Kenya: Expanding access to comprehensive reproductive health services at the community level. Afr J Midwifery Womens Health. 2013 Oct 1;7(4):171-7.

34. Diamond-Smith, N, M Sudhinaraset, D Montagu. Clinical and perceived quality of care for maternal, neonatal and antenatal care in Kenya and Namibia: the service provision assessment. Reprod Health. 2016 Aug 11;13:92. 
35. Oguntunde, O, Z Charyeva, M Cannon, W Sambisa, N Orobaton, IA Kabo et al. Factors influencing the use of magnesium sulphate in pre-eclampsia/eclampsia management in health facilities in Northern Nigeria: a mixed methods study. BMC Pregnancy Childbirth. 2015 Jun 3;15:130.

36. Jana, N, S Barik, N Arora. Re: Clinical practice patterns on the use of magnesium sulphate for treatment of pre-eclampsia and eclampsia: a multi-country survey. BJOG Int J Obstet Gynaecol. 125(7):909-909.

37. Bigdeli, M, S Zafar, H Assad, A Ghaffar. Health System Barriers to Access and Use of Magnesium Sulfate for Women with Severe Pre-Eclampsia and Eclampsia in Pakistan: Evidence for Policy and Practice. PLOS ONE. 2013 Mar 26;8(3):e59158.

38. Ishaku, S, B Ahonsi, J Tukur, O Ayodeji. Attrition from care after the critical phase of severe pre-eclampsia and eclampsia: Insights from an intervention with magnesium sulphate in a primary care setting in northern Nigeria. Health (N Y). 2013;05(09):1461-6.

39. Gagliardi, AR, F Webster, L Perrier, M Bell, S Straus. Exploring mentorship as a strategy to build capacity for knowledge translation research and practice: a scoping systematic review. Implement Sci. 2014 Sep 25;9:122.

40. Ajeani, J, RM Ayiasi, M Tetui, E Ekirapa-Kiracho, G Namazzi, RM Kananura et al. A cascade model of mentorship for frontline health workers in rural health facilities in Eastern Uganda: processes, achievements and lessons. Glob Health Action. 2017 Aug 1;10(sup4):1345497.

41. Ndwiga, C, T Abuya, R Mutemwa, JK Kimani, M Colombini, S Mayhew et al. Exploring experiences in peer mentoring as a strategy for capacity building in sexual reproductive health and HIV service integration in Kenya. BMC Health Serv Res. 2014 Mar 1;14:98.

42. Kawakatsu, Y, T Sugishita, K Oruenjo, S Wakhule, K Kibosia, E Were et al. Determinants of health facility utilization for childbirth in rural western Kenya: cross-sectional study. BMC Pregnancy Childbirth. 2014 Aug 9;14(1):265.

43. Colfer, CJP, R Achdiawan, JM Roshetko, E Mulyoutami, EL Yuliani, A Mulyana et al. The Balance of Power in Household Decision-Making: Encouraging News on Gender in Southern Sulawesi. World Dev. 2015 Dec 1;76:147-64.

44. The role of gender inequities in women's access to reproductive health care: a population-level study of Namibia, Kenya, Nepal, and India. www.ncbi.nlm.nih.gov/pmc/articles/PMC3422107

45. CEDAW $7^{\text {th }}$ Country Report. Kenya Ministry of Gender, Child and Social Development. 2011. www.gender.go.ke/index.php/downloads1/viewdownload/9 --- gender --- mainstreaming/7 --- cedaw --7th --- country --- report --- kenya

46. Schuler, SR, E Rottach, P Mukiri. Gender norms and family planning decision-making in Tanzania: a qualitative study. J Public Health Afr. 2011;2(2). www.ncbi.nIm.nih.gov/pmc/articles/PMC5345498

47. Izugbara, $\mathrm{CO}$ and DP Ngilangwa. Women, poverty and adverse maternal outcomes in Nairobi, Kenya. BMC Womens Health. 2010 Dec 1;10:33.

48. Vincent, $\mathrm{KZ}$ et al. Health-seeking behaviour during times of illness: a study among adults in a resource poor setting in Ghana | Journal of Public Health | Oxford Academic. 2015. https://academic.oup.com/jpubhealth/article/38/4/e545/2966942

49. Mwilike, B. et al. Knowledge of danger signs during pregnancy and subsequent healthcare seeking actions among women in Urban Tanzania: a cross-sectional study | BMC Pregnancy and Childbirth. 2018. https://bmcpregnancychildbirth.biomedcentral.com/articles/10.1186/s12884-017-1628-6 
50. Atuoye, NK. Can she make it? Transportation barriers to accessing maternal and child health care services in rural Ghana I BMC Health Services Research. https://bmchealthservres.biomedcentral.com/articles/10.1186/s12913-015-1005-y

51. Tamanna, KK et al. Barrier of Distance and Transportation Cost to Access Maternity Services in Rural Bangladesh. 2013. http://paa2013.princeton.edu/papers/132360

52. Wekesa, WE. Implementation challenges of free maternity services policy in Kenya: the health workers' perspective. ResearchGate.

www.researchgate.net/publication/287387291 Implementation challenges of free maternity services policy in Kenya the health workers $\% 27$ perspective

53. Nicole Bourbonnais. Implementing Free Maternal Health Care in Kenya; Challenges, Strategies, and Recommendations. 2013. www.knchr.org/Portals/O/EcosocReports

54. Charlotte E Warren. A cross sectional comparison of postnatal care quality in facilities participating in a maternal health voucher program versus non-voucher facilities in Kenya. 2015.

55. Mutemwa, R et al. Does service integration improve technical quality of care in low-resource settings? An evaluation of a model integrating HIV care into family planning services in Kenya. 2017.

56. Update on development ANC guidelines: Preliminary results from pilot studies on Group ANC. A presentation made for MNH TWG on 5th April 2018. Elizabeth Washika, Reprodcutive and Maternal Health Services Unit Ministry of Health, Kenya. 